\title{
Nematodes of the small intestine of African buffaloes, Syncerus caffer, in the Kruger National Park, South Africa
}

\author{
Authors: \\ William A. Taylor ${ }^{1,2}$ \\ John D. Skinner ${ }^{1, \dagger}$ \\ Joop Boomker ${ }^{3,4}$

\section{Affiliations:} \\ ${ }^{1}$ Centre for Veterinary \\ Wildlife Studies, Faculty \\ of Veterinary Science, \\ University of Pretoria, \\ South Africa
}

${ }^{2}$ Department of Zoology and Physiology, University of

Wyoming, United States of

America

${ }^{3}$ Department of Veterinary Tropical Diseases, University of Pretoria, South Africa

${ }^{4}$ Department of Zoology, University of Johannesburg, South Africa

Correspondence to: William Taylor

Email:

taylor.wa@gmail.com

Postal address:

PO Box 71664, Bryanston

2021, South Africa.

Dates:

Received: 08 Jan. 2013

Accepted: 18 Apr. 2013

Published: 16 May 2013

How to cite this article:

Taylor, W.A., Skinner,

J.D. \& Boomker, J., 2013,

'Nematodes of the small intestine of African buffaloes, Syncerus caffer, in the Kruger National Park, South Africa', Onderstepoort Journal of Veterinary Research 80(1), Art. \#562, 4 pages. http:// dx.doi.org/10.4102/ojvr. v80i1.562

Note:

†Prof. John D. Skinner passed away on 28 August 2011

Read online:
The abundance and distribution of parasitic helminths in populations of African buffaloes, Syncerus caffer, have not been well documented. A total of 28 buffaloes of different ages and sexes were sampled in the Kruger National Park, South Africa, for nematodes of the small intestine. Three nematode species were identified, namely Cooperia fuelleborni, Cooperia hungi and Trichostrongylus deflexus, with C. hungi being a new country record for African buffalo in South Africa. The overall prevalence was $71 \%$ and the average number of worms was 2346 (range: 0-15980). This is a small burden for such a large mammal. Sex, age and body condition of the buffaloes had no significant effect on worm occurrence.

\section{Communication}

Helminths of African buffaloes, Syncerus caffer, have not been well documented compared with many southern African ungulates (Boomker et al. 1996). Although at least 25 nematode species have been recorded in the gastro-intestinal tract (GIT) of buffaloes across Africa (with 13 of these recorded in South Africa), quantitative studies to date have used small sample sizes, such as four from the Kruger National Park (KNP), South Africa, and four from the Hluhluwe-iMfolozi Game Reserve (HiMGR), South Africa (Boomker et al. 1996). The average burdens from these two collections were 1086 and 2096 worms, respectively. Such numbers appear low for an animal the size of a buffalo and the general impression is that buffaloes do not harbour significant intestinal nematode burdens (Boomker et al. 1996). Basson et al. (1970) examined the carcasses of 100 buffaloes in the KNP for parasitic and other diseases and recorded nine helminth species in the GITs, but they did not document numbers or how the worms were distributed within the host population. Other large-scale studies of helminths in African buffaloes have been based on faecal egg counts (e.g. Caron, Cross \& Du Toit 2003; Penzhorn 2000), which do not identify nematodes at the species level and which cannot be considered reliable for assessing the size of nematode burdens (Penzhorn 2000; Reinecke 1983). Overall, therefore, we know little about the abundance and distribution of nematode communities in buffalo populations.

In 2005, South African National Parks (SANParks) performed a large-scale cull of buffaloes in the southern section of the KNP $\left(25^{\circ} \mathrm{S}, 31^{\circ} \mathrm{E}\right)$ to assess the prevalence of bovine tuberculosis. The culling method involved trained personnel shooting buffaloes from a helicopter, with up to 20 individuals being taken from a single herd in one day. Each herd was sampled once and culled animals approximately represented a random cross section of the population. Immediately after shooting, a large professional SANParks crew were available to locate all dead animals, which were quickly eviscerated in the field.

We obtained the small intestines (SI) of 28 buffaloes from four herds over four days during the cull (04-05 July 2005 and 18-19 July 2005). Time and personnel constraints prevented the processing of more samples. A cross section of buffalo genders and ages was taken, which included 16 male animals (seven of which were under two years of age) and 12 female animals (three of which were under two years of age) (Table 1). The field evisceration allowed quick access to the GIT of selected animals and we ligated their SIs within $1.5 \mathrm{~h}$ after death. Samples were then transported to a wet laboratory in the KNP for processing, where the parasites were collected based on procedures described by Horak (1978). Hearts, lungs and livers were not collected because they were required for tuberculosis analysis, whilst abomasa and large intestines were not examined owing to logistical constraints. Aliquots, each representing a twentieth of the volume of the SI contents, were collected for microscopic examination and stored in $10 \%$ formalin for later identification and counting. Permission for collecting this biological material was obtained from the Scientific Division of SANParks, whilst the ethics committee of the Faculty of Veterinary Science, University of Pretoria approved of our methods. KNP veterinary staff kindly provided data on the sex, age and body condition score of each animal. These variables were included in statistical models as potential predictors of worm burdens.

Copyright: (C) 2013. The Authors. Licensee: AOSIS OpenJournals. This work is licensed under the Creative Commons Attribution License. 
The degree of aggregation of the nematodes was estimated using the corrected moment estimate for aggregation $(\mathrm{k})$, where $k=\left(m^{2}-s^{2} / n\right) /\left(s^{2}-m\right)$ and $m$ denotes mean parasite burden, $s^{2}$ denotes variance and $n$ denotes sample size (Wilson et al. 2002). A value of $k<1$ indicates over-dispersion. Using the statistical software programme R ( R Development Core Team 2008), the effects of buffalo sex, age and body condition on nematode presence or absence were tested with logistic regression using the 'glm' function and binomial family. Buffalo sex (two categories) and body condition (five categories) were entered as factors, whilst age was entered as a continuous variable. To check the fit of the model, the difference between the residual deviance of the overall model (the model with three predictors) and the residual deviance of the null model (intercept only) was calculated, and this was used in a $\chi^{2}$ test with degrees of freedom ( $\left.d f\right)$ equal to the number of predictor variables. Goodness-of-fit of the model was verified with a separate $\chi^{2}$ test, also based on the residual deviance and degrees of freedom. The effects of the predictor variables on the nematode counts were tested with a generalised linear model using the negative binomial distribution (glm function, negative binomial family), because nematodes were over-dispersed (see results). The only model that converged was a reduced model with one predictor (age). Model fit and goodness-of-fit tests were based on residual deviance and degrees of freedom.

Three species of nematodes were identified, namely Cooperia fuelleborni, Cooperia hungi and Trichostrongylus deflexus, with an overall prevalence of $71 \%$ (Table 1 ). Adult nematode counts ranged from zero $(n=8)$ to $15980(n=1)$, with an average count of 2346 worms. The frequency distributions for the nematodes were highly aggregated $(k=0.35)$, indicating over-dispersion (Figure 1). Nematode larvae, which occurred in small numbers, were not counted.

For nematode presence or absence, the overall model did not fit the data significantly better than the null model (null deviance - residual deviance $=4.85$; null $d f-$ residual $d f=5.00$; $p=0.43$ ), indicating that none of the independent variables were good predictors of nematode infection. The goodnessof-fit test indicated that the logistic model fit the data $(p=0.16)$. For nematode counts, the overall negative binomial model did not converge, so a reduced model with a single predictor variable (age) was used. The reduced model did not fit the data significantly better than the null model (null deviance - residual deviance $=0.05$; null $d f-$ residual $d f=1.00$; $p=0.82$ ), indicating that buffalo age was not a good predictor of nematode burden. The goodness-of-fit test indicated that the negative binomial model fit the data $(p=0.21)$.

TABLE 1: Individual buffalo statistics and nematode infection results for 28 African buffaloes culled in the Kruger National Park, July 2005.

\begin{tabular}{|c|c|c|c|c|c|c|}
\hline Buffalo gender & $\begin{array}{l}\text { Buffalo age } \\
\text { (years) }\end{array}$ & $\begin{array}{l}\text { Buffalo body } \\
\text { condition score }\end{array}$ & $\begin{array}{l}\text { Total nematode } \\
\text { count }\end{array}$ & $\begin{array}{l}\text { Cooperia fuelleborni } \\
\text { count }\end{array}$ & $\begin{array}{l}\text { Cooperia hungi } \\
\text { count }\end{array}$ & $\begin{array}{l}\text { Trichostrongylus } \\
\text { deflexus count }\end{array}$ \\
\hline Female & 0.3 & 4.0 & 740 & 640 & 0 & 100 \\
\hline Female & 1.0 & 4.0 & 6760 & 6180 & 0 & 580 \\
\hline Female & 2.0 & 4.0 & 2080 & 2040 & 0 & 40 \\
\hline Female & 2.0 & 4.0 & 8180 & 7900 & 60 & 220 \\
\hline Female & 3.0 & 4.0 & 0 & 0 & 0 & 0 \\
\hline Female & 7.0 & 4.0 & 0 & 0 & 0 & 0 \\
\hline Female & 8.0 & 4.0 & 0 & 0 & 0 & 0 \\
\hline Female & 8.0 & 3.5 & 15980 & 15980 & 0 & 0 \\
\hline Female & 9.0 & 3.0 & 20 & 20 & 0 & 0 \\
\hline Female & 15 & 3.0 & 0 & 0 & 0 & 0 \\
\hline Male & 0.3 & 4.0 & 400 & 400 & 0 & 0 \\
\hline Male & 0.3 & 3.5 & 0 & 0 & 0 & 0 \\
\hline Male & 0.5 & 5.0 & 300 & 300 & 0 & 0 \\
\hline Male & 1.3 & 4.0 & 3260 & 3260 & 0 & 0 \\
\hline Male & 1.5 & 4.0 & 4400 & 4400 & 0 & 0 \\
\hline Male & 1.5 & 4.0 & 420 & 380 & 0 & 40 \\
\hline Male & 2.0 & 4.0 & 5440 & 5400 & 0 & 40 \\
\hline Male & 3.0 & 4.0 & 300 & 300 & 0 & 0 \\
\hline Male & 3.0 & 4.0 & 0 & 0 & 0 & 0 \\
\hline Male & 4.0 & 3.5 & 40 & 40 & 0 & 0 \\
\hline Male & 4.0 & 3.5 & 0 & 0 & 0 & 0 \\
\hline Male & 6.0 & 3.0 & 0 & 0 & 0 & 0 \\
\hline Male & 7.0 & 4.0 & 4000 & 3540 & 0 & 460 \\
\hline Male & 8.0 & 4.0 & 20 & 20 & 0 & 0 \\
\hline Male & 8.0 & 4.0 & 400 & 400 & 0 & 0 \\
\hline Prevalence & - & - & $71 \%$ & $71 \%$ & $7 \%$ & $32 \%$ \\
\hline
\end{tabular}

All nematode counts are for adult worms. 

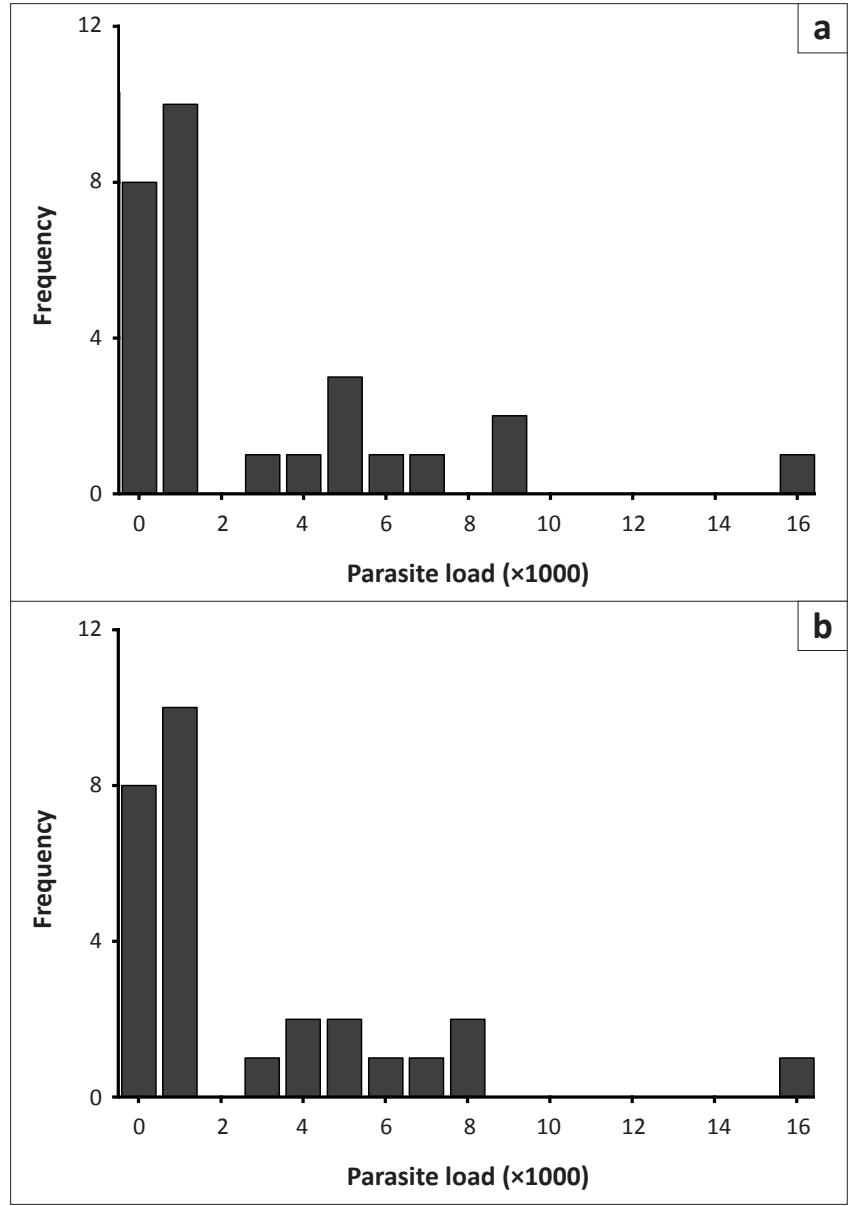

Corrected moment estimate for aggregation $(k)=\left(m^{2}-s^{2} / n\right) /\left(s^{2}-m\right)$ and $m=$ mean parasite burden, $s^{2}=$ variance, $n=$ sample size.

FIGURE 1: Observed frequency distributions of (a) all nematodes $(k=0.35)$ and (b) Cooperia fuelleborni $(k=0.34)$ in 28 African buffaloes.

Out of 13 nematode species so far known to occur in the GIT of African buffaloes in South Africa, six (Agriostomum gorgonis, C. fuelleborni, Cooperia pectinata, Cooperia punctata, Trichostrongylus axei and T. deflexus) had been found in the SI (Boomker et al. 1996). In the present study, C. hungi is a new country record, but not a new host record because it had previously been recorded in African buffaloes outside South Africa (Boomker et al. 1996). Many of the nematode species recorded previously had been collected incidentally (Boomker et al. 1996), so it is difficult to compare the number of species found in the present study (three species) with other studies. Basson et al. (1970) found four SI species in 100 buffaloes, but it is not clear how thoroughly these animals were examined. Worm burdens found in the present study are slightly higher than found previously, where four animals in the KNP had a mean burden of 1086 worms (range: 148-2017) and four animals in the HiMGR had a mean burden of 2096 worms (range: 0-8383) (Boomker et al. 1996). These earlier studies examined the entire GIT, whilst the present study included worms only from the SI. The high count of worms in the present study (15 980) is twice the largest burden found in previous studies (8383, in HiMGR), but this is probably the result of the larger sample size.

When compared with the average nematode burdens found in the SI of other South African grazing ungulate species, the average burden in buffaloes falls at the high end of the range. For example, mountain reedbuck, Redunca fulvorufula, in the Free State had an average SI burden of 2047 worms in 41 animals (Taylor et al. 2005), whilst bontebok, Damaliscus dorcus, in the Bontebok National Park had an average SI burden of 334 worms in 16 animals (Boomker \& Horak 1992). Given that African buffaloes are approximately 18 times larger than mountain reedbuck and 9 times larger than bontebok, these worm burdens are not high for their body size. To put these burdens in perspective: it has been estimated that 300000 infective larvae of Cooperia species need to be ingested to produce clinical signs in cattle (Reinecke 1983). This finding concurs with the statement of Boomker et al. (1996) that, taking the nematode species diversity into account, burdens are not significant and should not inconvenience buffaloes.

The nematodes were highly aggregated, as is common for parasite distributions (Wilson et al. 2002), with most buffaloes harbouring burdens less than the average of 2346 worms. With regard to the nematode occurrence in the present study, none of the independent variables included were good predictors in the buffalo. It is recognised, however, that the number of buffaloes collected $(n=28)$ represents a small sample, so the outcome of the generalised linear models, particularly the negative binomial model for nematode counts, should be treated with caution. Some studies have shown that male animals are more prone to parasitic infection than female animals (Wilson et al. 2002). One proposed explanation for such an observation is that higher testosterone levels suppress the immune system, but such a sex-dependent effect on nematode presence or absence was not apparent in this case. In fact, the average burden in female buffaloes (3783 worms) was higher than in male buffaloes (1189 worms), but the lack of convergence in the generalised linear model prevented statistical comparison.

\section{Acknowledgements}

Our thanks go to the late Ryno Watermeyer for assistance with nematode identification, Brian Kuhn and Ian Bredin for assistance during nematode collection in the KNP, and Louis van Schalkwyk, Peter Buss, Roy Bengis, At Dekker and the KNP Scientific Services for logistic assistance and providing permits. Two anonymous referees helped improve the manuscript. The study was funded by the University of Pretoria.

\section{Competing interests}

The authors declare that they have no financial or personal relationships that may have inappropriately influenced them in writing this article.

\section{Authors' contributions}

W.A.T. (University of Pretoria and University of Wyoming) collected and identified the nematodes and wrote the manuscript. J.D.S. (University of Pretoria) funded the 
fieldwork and assisted with project design and scientific feedback. J.B. (University of Pretoria and University of Johannesburg) assisted with the project design and equipment, scientific feedback, nematode identification and manuscript comments.

\section{References}

Basson, P.A., McCully, R.M., Kruger, S.P., Van Niekerk, J.W., Young, E. \& De Vos, V. 1970 'Parasitic and other diseases of the African buffalo in the Kruger National Park', Onderstepoort Journal of Veterinary Research 37, 11-28. PMid:5535831

Boomker, J. \& Horak, I.G., 1992, 'Parasites of South African wildlife. XIII. Helminths of grey rhebuck, Pelea capreouls, and of bontebok, Damaliscus dorcus dorcus, in
the Bontebok National Park', Onderstepoort Journal of Veterinary Research 59, 175-182. PMid:1437019

Boomker, J., Horak, I.G., Penzhorn, B.L. \& Keet, D.F., 1996, 'Parasites of African buffaloes: A documentation', in B.L. Penzhorn (ed.), Proceedings of a symposium on the African buffalo as a game ranch animal, pp. 90-103, Onderstepoort, on the Afric
Pretoria.
Caron, A., Cross, P.C. \& Du Toit, J.T., 2003, 'Ecological implications of bovine tuberculosis in African buffalo herds', Ecological Applications 13, 1338-1345. http://dx.doi.org/10.1890/02-5266

Horak, I.G., 1978, 'Parasites of domestic and wild animals in South Africa. X. Helminths in impala', Onderstepoort Journal of Veterinary Research 45, 221-228. PMid:572950

Penzhorn, B.L., 2000, 'Coccidian oocyst and nematode egg counts of free-ranging African buffalo (Syncerus caffer) in the Kruger National Park, South Africa', Journal of the South African Veterinary Association 71, 106-108. http://dx.doi. org/10.4102/jsava.v71i2.689, PMid:11030361

R Development Core Team, 2008, R: A language and environment for statistical computing, R Foundation for Statistical Computing, Vienna.

Reinecke, R.K., 1983, Veterinary helminthology, Butterworths, Pretoria.

Taylor, W.A., Boomker, J., Krecek, R.C., Skinner, J.D. \& Watermeyer, R., 2005, 'Helminths in sympatric populations of mountain reedbuck (Redunca fulvorufula) and gray rhebok (Pelea capreolus) in South Africa', Journal of Parasitology 91, 863-870. rhebok (Pelea capreolus) in South Africa', Journal of Parc
http://dx.doi.org/10.1645/GE-436R.1, PMid:17089756

Wilson, K., Bjornstad, O.N., Dobson, A.P., Merler, S., Poglayen, G., Randolph, S.E., Read, A.F. \& Skorping, A., 2002, 'Heterogeneities in macroparasitic infections: Patterns and processes', in P.J. Hudson, A. Rizzoli, B.T. Grenfell, J.A.P. Heesterbeek Patterns and processes, in P.J. Hudson, A. Rizzoli, B.T. Grenfell, J.A.P. Heesterbeek
(eds.), The ecology of wildlife diseases, pp. 6-44, Oxford University Press, Oxford. (eds.), The ecology 